\title{
MicroRNA-204-5p inhibits the osteogenic differentiation of ankylosing spondylitis fibroblasts by regulating the Notch 2 signaling pathway
}

\author{
JIANJUN ZHAO ${ }^{1}$, YANYAN ZHANG ${ }^{2}$ and $\mathrm{BO} \mathrm{LIU}^{3}$
}

Departments of ${ }^{1}$ Joint Surgery and Traumatic Orthopedics and ${ }^{2}$ General Surgery, Shouguang People's Hospital, Shouguang, Shandong 262700; ${ }^{3}$ Department of Trauma Orthopedics, The No. 4 Hospital of Jinan, Jinan, Shandong 250031, P.R. China

Received October 12, 2019; Accepted June 5, 2020

DOI: $10.3892 / \mathrm{mmr} .2020 .11303$

\begin{abstract}
Ankylosing spondylitis (AS) is a chronic inflammatory systemic disease and is difficult to detect in the early stages. The present study aimed to investigate the role of microRNA ( $m i R)$-204-5p in osteogenic differentiation of AS fibroblasts. Bone morphogenetic protein 2 (BMP-2) was used to induce osteogenic differentiation. Cells were divided into the following groups: AS group, AS + BMP-2 group, AS + BMP-2 + miR-negative control group, AS + BMP-2 + miR-204-5p mimics group and $\mathrm{AS}+\mathrm{BMP}-2+m i R-204-5 p$ mimics + pcDNA-Notch2 group. The expression levels of $m i R-204-5 p$, Notch2, runt-related transcription factor 2 (RUNX2) and osteocalcin were detected via reverse transcription-quantitative PCR analysis. The binding site between Notch 2 and $m i R-204-5 p$ was predicted using TargetScan software and verified via the dual-luciferase reporter assay. Alkaline phosphatase (ALP) activity was assessed via the ALP assay, while the mineralized nodules area was determined via the Alizarin Red S staining assay. The results demonstrated that Notch2 is a target gene of $m i R-204-5 p$. Furthermore, treatment with BMP-2 significantly decreased miR-204-5p expression, and significantly increased ALP activity, the mineralized nodules area and the expression levels of Notch2, RUNX2 and osteocalcin in ligament fibroblasts (all $\mathrm{P}<0.05$ ). Conversely, transfection with $m i R-204-5 p$ mimics significantly increased $m i R-204-5 p$ expression, and significantly decreased ALP activity, the mineralized nodules area and the expression levels of Notch2, RUNX2 and osteocalcin in ligament fibroblasts (all $\mathrm{P}<0.05$ ). Notably, transfection with pcDNA-Notch2 significantly reversed the inhibitory effects induced by miR-204-5p mimics
\end{abstract}

Correspondence to: $\mathrm{Dr}$ Bo Liu, Department of Trauma Orthopedics, The No. 4 Hospital of Jinan, 50 Shifan Road, Jinan, Shandong 250031, P.R. China

E-mail: libo20199@163.com

Key words: ankylosing spondylitis, miRNA-204-5p, Notch2, osteogenic differentiation, ligament fibroblasts on the osteogenic differentiation of ligament fibroblasts (all $\mathrm{P}<0.05$ ). Furthermore, $m i R-204-5 p$ inhibited the osteogenic differentiation of ligament fibroblasts in patients with AS by targeting Notch2. Thus, $m i R-204-5 p$ may negatively regulate Notch2 expression and may be a potential therapeutic target for AS. Collectively, the results of the present study provide a theoretical basis for the effective treatment of patients with AS.

\section{Introduction}

Ankylosing spondylitis (AS) is a common chronic immune-mediated joint disease, which predominantly affects the spine and pelvis (1). Between May 2005 and May 2019, the total prevalence of AS in mainland China was $0.29 \%$ (2). AS is characterized by spinal pain, stiffness and new bone formation, which manifests ligament atrophy and joint stiffness (3). A previous study has demonstrated that there is no definite value in assessing the long-term prognosis and mortality of patients with AS (4). The number of patients with AS per 10,000 people is 23.8 in Europe, 16.7 in Asia, 31.9 in North America, 10.2 in Latin America and 7.4 in Africa (5). With the increasing incidence of AS, the therapeutic strategies of AS are also diversified, including the use of tumor necrosis factor blockers (6), radiotherapy (7), ultrasound combined exercise therapy (8) and surgical treatment (9). Furthermore, microRNAs (miRNAs/miRs) play a key role in regulating the immune function and autoimmunity (10). With the development of molecular targeting technology, research on miRNAs is of great interest for the treatment of AS.

miRNAs play a significant role in AS pathology by targeting the inflammation and bone remodeling genes (11). Notably, miR-204 regulates the transformation of mesenchymal stem cells into adipose and osteoblast cell lines (12). miR-204 is involved in the development of several diseases. For example, $m i R-204-5 p$ plays a therapeutic role in aplastic anemic rats via the NF-kB signaling pathway (13), which is a target for AS treatment (14). Furthermore, the maintain bone morphogenetic protein (BMP)/SMAD (15), Wnt/ $\beta$-catenin (16) and Notch (17) signaling pathways are involved in the process of AS. Specifically, the Notch2 signaling pathway is required to promote cell proliferation and maintain BMP signaling (18). 
There is a positive regulatory association between the Notch and NF- $\kappa \mathrm{B}$ signaling pathways (19). However, whether $m i R-204-5 p$ is involved in the regulation of the Notch signaling pathway, and whether it has an impact on osteogenic differentiation of AS fibroblasts have not yet been fully investigated.

BMP-2 is a member of the transforming growth factor- $\beta$ superfamily that is synthesized and secreted by osteoblasts (20). BMP-2 is considered a common osteogenic agent, which can induce undifferentiated mesenchymal cells into cartilage and bone tissues (21). A previous study demonstrated that BMP-2 facilitates the osteogenic differentiation of bone marrow-derived mesenchymal stem cells by inducing alkaline phosphatase (ALP) activity, promoting mineralization, enhancing adherence and mediating the expression and activation of osteogenic markers (22).

In the current study mRNA expression was detected using reverse transcription-quantitative PCR (RT-qPCR). The binding site between Notch 2 and $m i R-204-5 p$ was predicted using TargetScan software and assessed via the dual-luciferase reporter assay. Moreover, ALP activity was assessed via the ALP assay, while the mineralized nodules area was determined via the Alizarin Red S staining assay. In addition, BMP-2 was used to induce osteogenic differentiation of AS fibroblasts, and the regulatory role of $m i R-204-5 p$ on the osteogenic differentiation of AS fibroblasts, and the underlying molecular mechanism involving the Notch signaling pathway were assessed. Taken together, the results of the present study provide a theoretical basis for the treatment of patients with AS.

\section{Materials and methods}

Primary culture of ligament fibroblasts. A total of 20 patients with AS (20 men; age, 25-39 years; mean age, 30.2 years) who underwent surgical intervention at Shouguang People's Hospital between January 2016 and January 2018 were recruited in the present study. The bioptic tissues were collected from the 20 patients with AS. All patients were in the active stage, exhibiting inflammatory low back pain, notable ossification of the ankle joint, positive histocompatibility leukocyte antigen (HLA)-B27, and elevated levels of C-reactive protein and erythrocyte sedimentation rate (ESR). All patients met the New York Standard of the American College of Rheumatology revised in 1984 (23).

A total of 20 patients (20 men; age, 26-43 years; mean age, 31.5 years) who underwent hip arthroplasty for femoral neck fracture (excluding other types of osteoarthritis) between January 2017 and October 2017 were recruited as the control group in the present study. The hip ligament tissues were washed with physiological saline, immediately frozen in liquid nitrogen and stored at $-80^{\circ} \mathrm{C}$ until further experimentation. The present study was approved by the Ethics Committee of Shouguang People's Hospital (approval no. SGSRMXY-2020-09) and written informed consent was provided by all patients prior to the study start.

The hip ligament tissues of patients with AS were rinsed three times with PBS supplemented with $300 \mathrm{U} / \mathrm{ml}$ penicillin and $300 \mu \mathrm{g} / \mathrm{ml}$ streptomycin (all Gibco; Thermo Fisher Scientific, Inc.). The ligament tissues were subsequently cut into $1-\mathrm{mm}^{3}$-thick sections using ophthalmic scissors, and added into plates containing $5 \mathrm{ml}$ serum-free DMEM medium and $0.2 \mu \mathrm{g} / \mathrm{ml}$ type I collagenase (all Invitrogen; Thermo Fisher Scientific, Inc.). The collagen fibers were removed by filtration at $1,000 \mathrm{r} / \mathrm{min}$, through a $0.22 \mu \mathrm{m}$ filter (EMD Millipore). The precipitated cells were cultured in DMEM medium supplemented with $20 \%$ serum and $1 \%$ streptomycin, at $37^{\circ} \mathrm{C}$ in $5 \% \mathrm{CO}_{2}$ for $72 \mathrm{~h}$.

Osteogenic differentiation of ligament fibroblasts. The osteogenic differentiation of ligament fibroblasts was induced by BMP-2 as previously described (24-26). Cells were divided into the following groups: AS group, $\mathrm{AS}+\mathrm{BMP}-2$ group, AS + BMP-2 + miR-negative control (NC) group, AS + BMP-2 + miR-204-5p mimics group and AS + BMP-2 + miR-204-5p mimics + pcDNA-Notch2 group. Cells were transfected with $50 \mathrm{nmol} / 1 \mathrm{miR}-204-5 \mathrm{p}$ mimics, miR-NC, pcDNA-Notch2 or pcDNA-NC (Shanghai GenePharma Co.,Ltd.), using Lipofectamine ${ }^{\circledR} 2000$ transfection reagent (Thermo Fisher Scientific, Inc.). The subsequent experiments were performed at $24 \mathrm{~h}$ post-transfection. Subsequently, cells were cultured in DMEM/H containing $10 \%$ fetal bovine serum, $0.05 \mathrm{mM}$ vitamin $\mathrm{C}$ and $100 \mathrm{mM}$ dexamethason (all Gibco; Thermo Fisher Scientific, Inc.). BMP-2 (200 ng/ml; Sigma-Aldrich; Merck KGaA) was added to all medium except the AS group. All cells were cultured in $5 \% \mathrm{CO}_{2}$ at $37^{\circ} \mathrm{C}$ and induced for 14 days.

Reverse transcription-quantitative $(R T-q) P C R$. Total RNA was extracted from the hip ligament tissues and ligament fibroblasts using TRIzol ${ }^{\circledR}$ reagent (Invitrogen; Thermo Fisher Scientific, Inc.). Synthesis of cDNA using reverse transcriptase was performed with the PrimeScript RT Enzyme Mix I kit (Takara Bio, Inc.). The reaction mixtures were incubated at $37^{\circ} \mathrm{C}$ for $60 \mathrm{~min}, 95^{\circ} \mathrm{C}$ for $5 \mathrm{~min}$ and then held at $4^{\circ} \mathrm{C}$. A total of $5 \mu$ l diluted RNA (1:20) was used to determine the concentration and purity of total RNA. miScript SYBR Green PCR kit (Qiagen, Inc.) was used to conduct the qPCR analysis. RT-qPCR was performed on an ABI7500 quantitative PCR machine (Thermo Fisher Scientific, Inc.). U6 was used as the internal control for miRNAs, and GAPDH served as the internal control for other genes. The primer sequences (Guangzhou Ruibo Biotechnology Co., Ltd.) are listed in Table I. The reaction conditions were as follows: $95^{\circ} \mathrm{C}$ for $10 \mathrm{~min}$, followed by 40 cycles at $95^{\circ} \mathrm{C}$ for $10 \mathrm{sec}, 60^{\circ} \mathrm{C}$ for $20 \mathrm{sec}$ and $72^{\circ} \mathrm{C}$ for $34 \mathrm{sec}$. Relative expression levels were calculated using the $2^{-\Delta \Delta \mathrm{Cq}}$ method (27).

ALP staining and calcium salt deposition staining. After 7 days of culturing, cells $\left(1 \times 10^{4}\right.$ cells/well) from each group were collected and fixed. ALP activity was assessed using the ALP activity assay kit (cat. no. A059-2-2; Nanjing Jiancheng Bioengineering Institute) according to the manufacturer's protocol. ALP activity was measured at a wavelength of $520 \mathrm{~nm}$, using a microplate reader (Molecular Devices LLC).

After 14 days of culturing, cells from each group were collected and stained with $2 \%$ Alizarin Red staining solution (pH 8.3; Nanjing KeyGen Biotech Co., Ltd.) at $37^{\circ} \mathrm{C}$ for $10 \mathrm{~min}$. The solution was discarded, cells were washed with PBS and subsequently observed under a phase contrast microscope 
Table I. Primer sequences used for quantitative PCR.

\begin{tabular}{ll}
\hline Gene & \multicolumn{1}{c}{ Sequence (5'-3') } \\
\hline$m i R-204-5 p(\mathrm{~F})$ & TTCCCTTTGTCATCCTATGCCT \\
$m i R-204-5 p(\mathrm{R})$ & TGGTGTCGTGGAGTCG \\
U6 (F) & GCTTCGGCAGCACATATACTAAAAT \\
U6 (R) & CGCTTCACGAATTTGCGTGTCAT \\
Notch2 (F) & CACAGGGTTCATAGCCATCTC \\
Notch2 (R) & GGAGGCGACCGAGAAGAT \\
RUNX2 (F) & AGCTTCTGTCTGTGCCTTCTGG \\
RUNX2 (R) & GGAGTAGAGAGGCAAGAGTTT \\
Osteocalcin (F) & CTTTGTGTCCAAGCAGGA \\
Osteocalcin (R) & CTGAAAGCCGATGTGGTCAE \\
GAPDH (F) & GAAGGTGAAGGTCGGAGTC \\
GAPDH (R) & GAAGATGGTGATGGGATTTC
\end{tabular}

F, forward; R, reverse; miR, microRNA; RUNX2, runt-related transcription factor 2 .

(light microscope), and the mineralized nodules area was counted at five high-power fields (magnification, x100).

Western blotting. Ligament fibroblasts were lysed using RIPA lysate (Beyotime Institute of Biotechnology) at $4^{\circ} \mathrm{C}$ for $30 \mathrm{~min}$. The supernatants were collected via centrifugation at $7,200 \mathrm{x} \mathrm{g}$ at $4^{\circ} \mathrm{C}$ for $10 \mathrm{~min}$. Total protein was quantified using the bicinchoninic acid assay kit (Beyotime Institute of Biotechnology) and $60 \mu \mathrm{g}$ protein/lane was separated via $10 \%$ separating gum and 5\% concentrating gum. The separated proteins were subsequently transferred onto polyvinylidene difluoride membranes and blocked with 5\% skim milk for $1 \mathrm{~h}$ at $37^{\circ} \mathrm{C}$. The membranes were incubated with primary antibodies against: Notch2 (cat. no. ab8926), runt-related transcription factor 2 (RUNX2; cat. no. ab23981), osteocalcin (cat. no. ab93876), GAPDH (cat. no. ab9485) and rabbit anti-human (all 1:5,000 and from Abcam) overnight at $4^{\circ} \mathrm{C}$. Following the primary incubation, membranes were incubated with horseradish peroxidase-labeled goat-anti-rabbit IgG secondary antibody (1:5,000; ca. no. ab6721; Abcam) for $1 \mathrm{~h}$ at $25^{\circ} \mathrm{C}$. The protein blots were visualized using an enhanced chemiluminescence kit (Invitrogen; Thermo Fisher Scientific, Inc.). Protein bands were assessed using a luminescent image analysis software (Quantity One 1-D Analysis software; version 4.6.9; Bio-Rad Laboratories, Inc.). GAPDH was used as the internal control.

Dual-luciferase reporter assay. TargetScan software v3.0 (http://starbase.sysu.edu.cn.) was used to predict the targeting relationship between miR-204-5 and Notch2. A 3'-untranslated region (UTR) wild type (WT) plasmid of Notch2 (Notch2-3'-UTR-WT) was constructed according to the 3'-UTR sequence of Notch 2. Based on this plasmid, a binding site was mutated to construct a 3'-UTR mutant (MUT) plasmid (Notch2-3'-UTR-MUT). The construction and sequencing of the plasmids were performed by Sangon Biotech Co., Ltd. Subsequently, the constructed luciferase reporter plasmids, pmirGLO-Notch2-WT/pmirGLO-Notch2-MUT (Shanghai
GenePharma Co., Ltd.) and $m i R-204-5 p$ mimics/miR-NC were co-transfected into $293 \mathrm{~T}$ cells (American Type Culture Collection) using Lipofectamine ${ }^{\circledR} 2000$ transfection reagent (Thermo Fisher Scientific, Inc.). The luciferase activity was measured using the dual luciferase activity assay kit (Thermo Fisher Scientific, Inc.), $48 \mathrm{~h}$ post-transfection, and was normalized to Renilla luciferase activity.

Statistical analysis. Statistical analysis was performed using SPSS software (version 21.0; IBM Corp.) and data are presented as the mean \pm standard deviation. All experiments were repeated three times. Unpaired Student's t-test was used to compare differences between two groups. One-way analysis of variance followed by Tukey's post hoc test was used to compare differences between multiple groups. $\mathrm{P}<0.05$ was considered to indicate a statistically significant difference.

\section{Results}

Downregulation of miR-204-5p in hip capsules of patients with AS. miR-204-5p expression was significantly lower in the hip joint capsules of patients with AS than in patients with femoral neck fracture $(\mathrm{P}<0.05$; Fig. 1A). Additionally, miR-204-5p expression was significantly decreased in BMP-2-induced AS cells compared with untreated-cells $(\mathrm{P}<0.05$; Fig. 1B). Furthermore, transfection of $m i R-204-5 p$ mimics significantly increased $m i R-204-5 p$ expression in BMP-2-induced AS cells $(\mathrm{P}<0.05$; Fig. 1B).

Upregulation of Notch2 expression in hip capsules of patients with AS. Notch 2 mRNA expression was significantly higher in the hip joint capsules of patients with AS than that in patients with femoral neck fracture $(\mathrm{P}<0.05$; Fig. 2A). Notch2 expression was significantly higher in the AS + BMP-2 group compared with the AS group, at both the mRNA and protein levels $(\mathrm{P}<0.05$; Fig. $2 \mathrm{~B}$ and $\mathrm{C})$. Furthermore, the mRNA and protein levels of Notch2 were significantly decreased in the AS + BMP-2 + miR-204-5p mimics group compared with those in the AS + BMP-2 + miR-NC group ( $\mathrm{P}<0.05$; Fig. 2B and $\mathrm{C})$.

Notch2 is a target gene of miR-204-5p. The binding site for Notch 2 and $m i R-204-5 p$ was predicted using TargetScan software (Fig. 3A). The luciferase activity of cells co-transfected with miR-204-5p mimics and pmirGLO-Notch2-WT was significantly lower than those co-transfected with $m i R-204-5 p$ mimics and pmirGLO-Notch2-MUT ( $\mathrm{P}<0.05$; Fig. 3B).

miR-204-5p inhibits osteogenic differentiation of ligament fibroblasts by targeting Notch2. The ALP activity of the AS + BMP-2 group was higher than that in the AS group $(\mathrm{P}<0.01$; Fig. 4A). Furthermore, the ALP activity in the AS + BMP-2 + miR-204-5p mimics group was significantly lower than that in the AS + BMP- + miR-NC group $(\mathrm{P}<0.01$; Fig. 4A). Notably, transfection with pcDNA-Notch2 significantly reversed the inhibitory effect induced by miR-204-5p mimics on the ALP activity of ligament fibroblasts $(\mathrm{P}<0.05$; Fig. 4A).

The mineralized nodules area in the AS + BMP-2 group was significantly increased compared with the AS group $(\mathrm{P}<0.01$; 
A

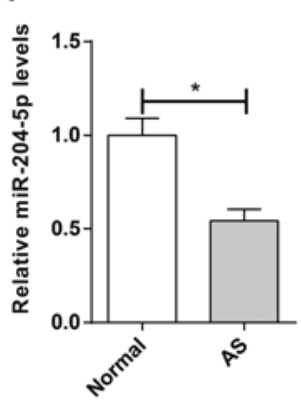

B

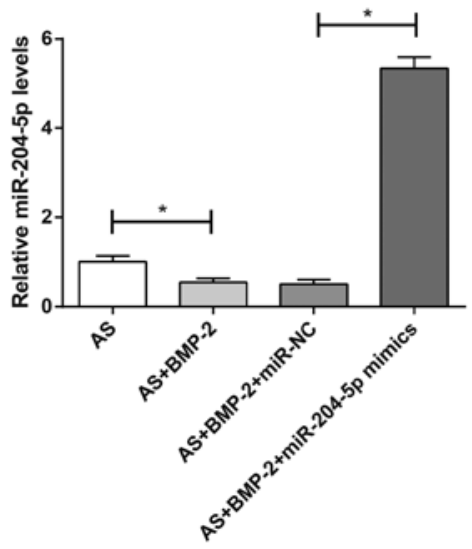

Figure 1. $m i R-204-5 p$ expression in hip joint capsule tissues and ligament fibroblasts. (A) $m i R-204-5 p$ expression in hip joint capsule tissues. (B) $m i R-204-5 p$ expression in AS-derived ligament fibroblasts. U6 was used as the internal control. " $\mathrm{P}<0.05$. miR, microRNA; AS, ankylosing spondylitis; BMP-2, bone morphogenetic protein 2; NC, negative control.

Fig. 4B). Furthermore, the mineralized nodules area in the $\mathrm{AS}+\mathrm{BMP}-2+m i R-204-5 p$ mimics group was significantly decreased compared with the AS + BMP-2 + miR-NC group $(\mathrm{P}<0.01$; Fig. 4B). Notably, transfection with pcDNA-Notch2 significantly reversed the inhibitory effect induced by miR-204-5p mimics on the mineralized nodules area of ligament fibroblasts $(\mathrm{P}<0.05$; Fig. 4B).

miR-204-5p inhibits the expression of RUNX2 and osteocalcin by targeting Notch2. Transfection with pcDNA-Notch2 significantly increased Notch2 protein expression in ligament fibroblasts $(\mathrm{P}<0.01$; Fig. 5A). The expression of RUNX2 and osteocalcin in the AS + BMP-2 group were significantly increased compared with the AS group, at both the mRNA and protein levels $(\mathrm{P}<0.01$; Fig. $5 \mathrm{~B}$ and $\mathrm{C})$. Furthermore, the expression of RUNX2 and osteocalcin in the $\mathrm{AS}+\mathrm{BMP}-2+m i R-204-5 p$ mimics group were significantly decreased compared with the AS + BMP-2 + miR-NC group, at both the mRNA and protein levels $(\mathrm{P}<0.01$; Fig. 5B and $\mathrm{C})$. Notably, transfection with pcDNA-Notch2 significantly reversed the inhibitory effect induced by miR-204-5p mimics on the expression of RUNX2 and osteocalcin in ligament fibroblasts $(\mathrm{P}<0.05$; Fig. $5 \mathrm{~B}$ and $\mathrm{C})$.

\section{Discussion}

AS is an autoimmune disease characterized by fibroblast ossification (28). Notably, inhibition of the ossification of AS fibroblasts is a common treatment for patients with AS (28). The present study aimed to determine whether miR-204-5p regulates the Notch signaling pathway, and subsequently affects the osteogenic differentiation of AS fibroblasts. The results demonstrated that $m i R-204-5 p$ expression decreased in the hip capsule tissues of patients with AS, and Notch2 was identified as the target gene of $m i R-204-5 p$. Furthermore, $m i R-204-5 p$ inhibited the osteogenic differentiation of AS fibroblasts by downregulating the expression of Notch2, RUNX2 and osteocalcin. Heterotopic ossification is one of the most prominent features of AS (29), and osteogenic
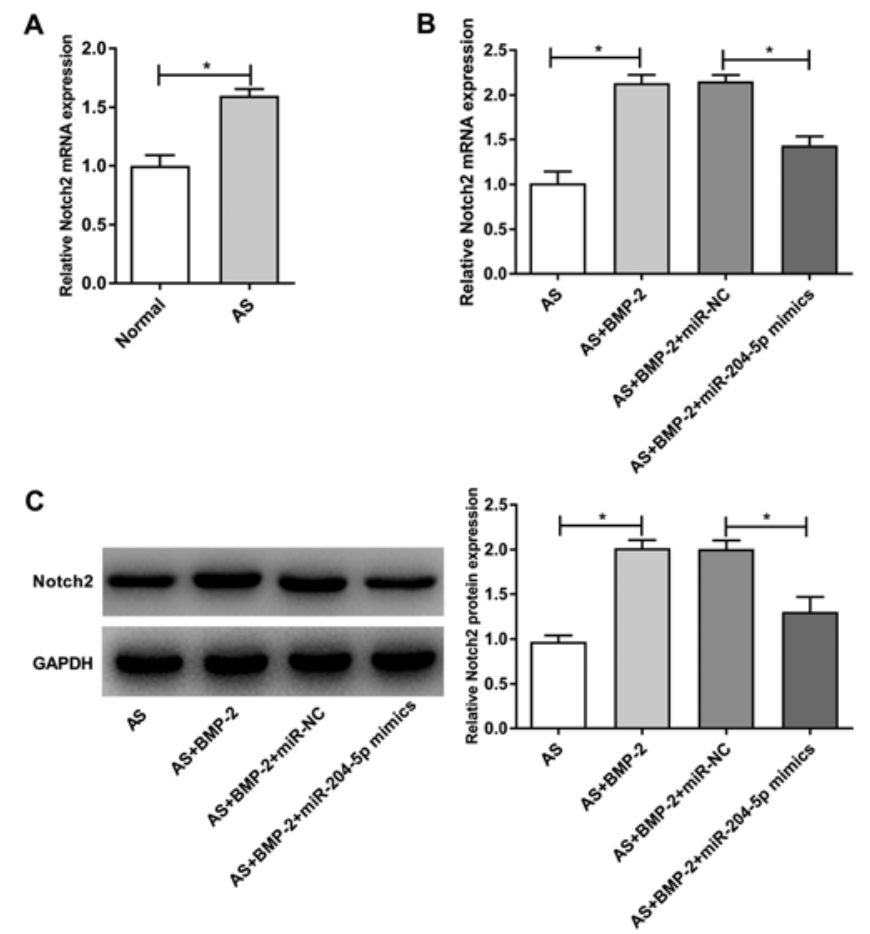

Figure 2. Notch2 expression in hip joint capsule tissues and ligament fibroblasts. (A) Notch2 expression in hip joint capsule tissues. (B) Notch2 mRNA expression in AS-derived ligament fibroblasts. (C) Notch2 protein expression in AS-derived ligament fibroblasts. GAPDH was used as the internal control. ${ }^{*} \mathrm{P}<0.05$. AS, ankylosing spondylitis; BMP-2, bone morphogenetic protein 2; $\mathrm{NC}$, negative control; miR, microRNA.

differentiation of fibroblasts plays a key role in the heterotopic ossification of AS (30). miRNAs play important roles in regulating cell-cell interactions between osteoclasts and fibroblasts (31). For example, $m i R-204-5 p$ is involved in the adjustability of adipogenesis and osteogenic differentiation of bone marrow stem cells (32). Zhang et al (33) reported that downregulating $m i R-204-5 p$ expression increases RUNX2 expression and promotes osteoblast proliferation. Consistent with previous findings, the results of the present study demonstrated the overexpression of $m i R-204-5 p$ inhibited RUNX2 expression, thereby inhibiting osteogenic differentiation of fibroblasts. In addition, overexpression of miR-204 has been reported to promote adipocyte differentiation and inhibit osteogenic differentiation, while miR-204 knockdown exerts the opposite effects (34). Taken together, these results suggest that $m i R-204-5 p$ inhibits osteogenic differentiation, and thus can be used to treat patients with AS.

The results of the present study demonstrated that $m i R-204-5 p$ inhibited the osteogenic differentiation of fibroblasts by targeting Notch2. Lee et al (35) and Cai et al (36) have reported that Notch2 is a target gene of miR-204-5p. In addition, Notch family members and their ligands are involved in the formation of articular cartilage at different locations, and the coordination of the ossification and extension of growth plates (37). Notably, the Notch signaling pathway significantly enhances BMP-2-induced osteogenesis of embryonic fibroblasts (38). BMP-2 is a well-known bone formation stimulating factor (39). However, downregulation of miR-204 expression by BMP-2 increases RUNX2 expression and enhances osteogenic differentiation (40). $m i R-204-5 p$ also 
A

\begin{tabular}{l|l}
\hline & $\begin{array}{r}\text { Predicted consequential pairing of target region (top) } \\
\text { and miRNA (bottom) }\end{array}$ \\
\hline Position 2534-2541 of Notch2 3'-UTR & $5, \quad$. GUGUGGUUCUAAUAAAGGGAA... \\
hsa-miR-204-5p & 3' $\quad$ UCCGUAUCCUACUGUUUCCCUU
\end{tabular}

B

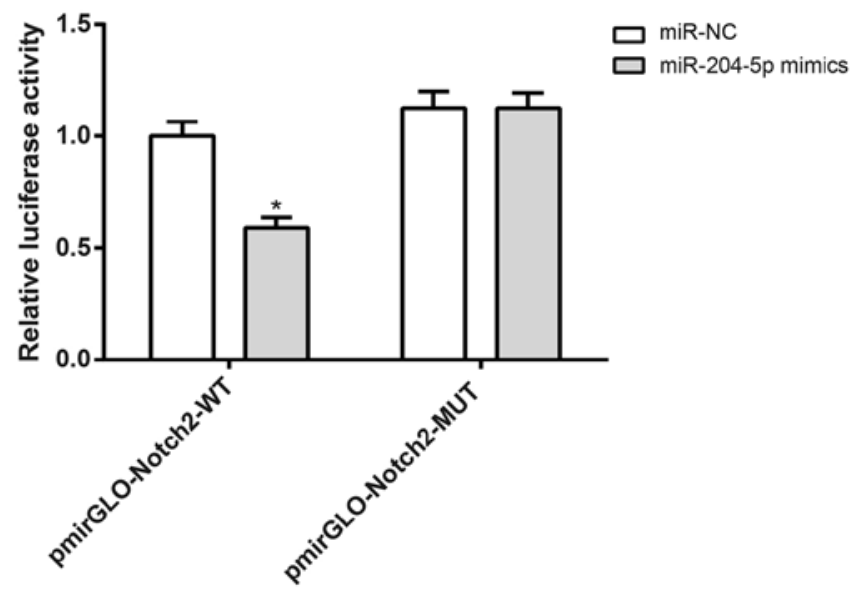

Figure 3. Notch2 is the target gene of $m i R-204-5 p$. (A) The target site for Notch2 and miR-204-5p was predicted using TargetScan software. (B) Detection of dual-luciferase reporter activity. ${ }^{*} \mathrm{P}<0.05$ vs. the miR-NC group. miR, microRNA; NC, negative control; UTR, untranslated region; WT, wild-type; MUT, mutant.

A
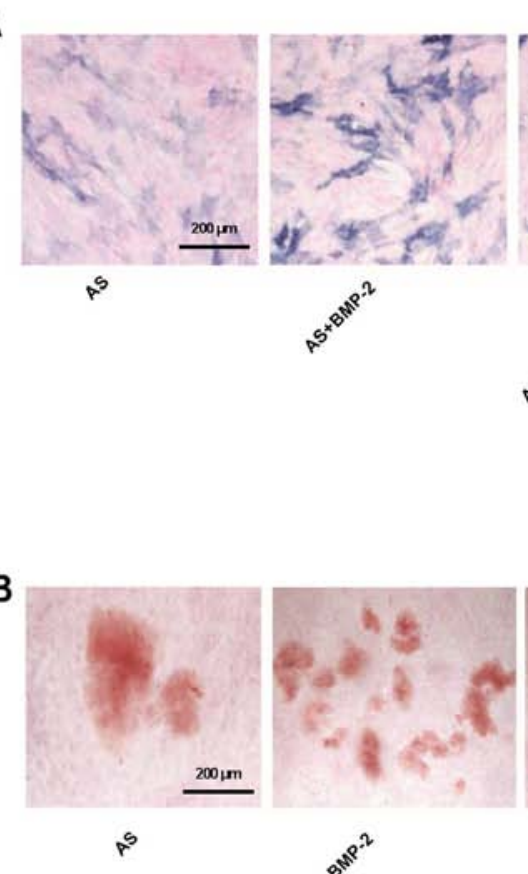
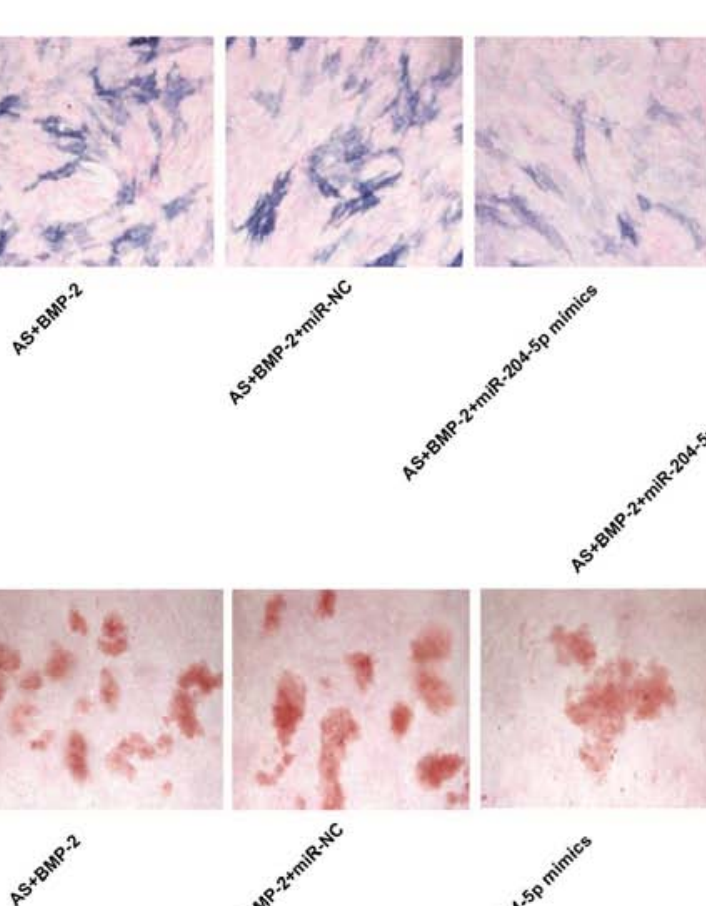
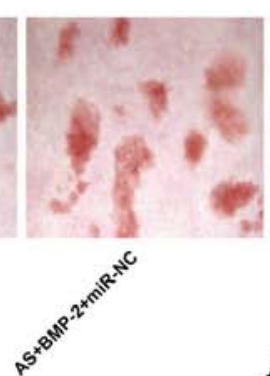
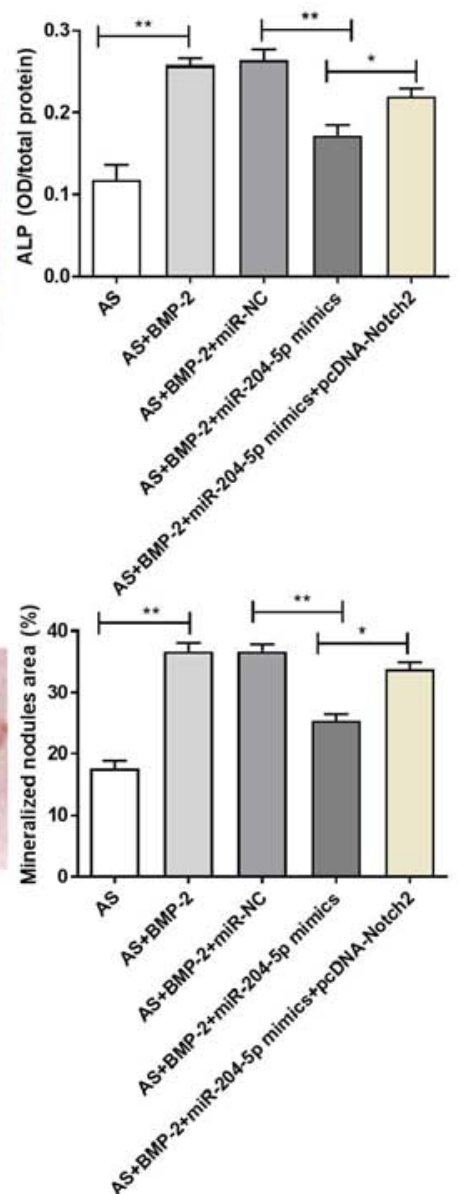

Figure 4. miR-204-5p inhibits the osteogenic differentiation of ligament fibroblasts by targeting Notch2. (A) ALP staining and (B) Alizarin Red S staining. ${ }^{*} \mathrm{P}<0.05$ vs. the AS + BMP- $2+$ miR-204-5p mimics group; ${ }^{* *} \mathrm{P}<0.01$ vs. the AS and AS + BMP-2 + miR-NC groups, respectively. miR, microRNA; ALP, alkaline phosphatase; AS, ankylosing spondylitis; BMP-2, bone morphogenetic protein 2; NC, negative control; OD, optical density. 

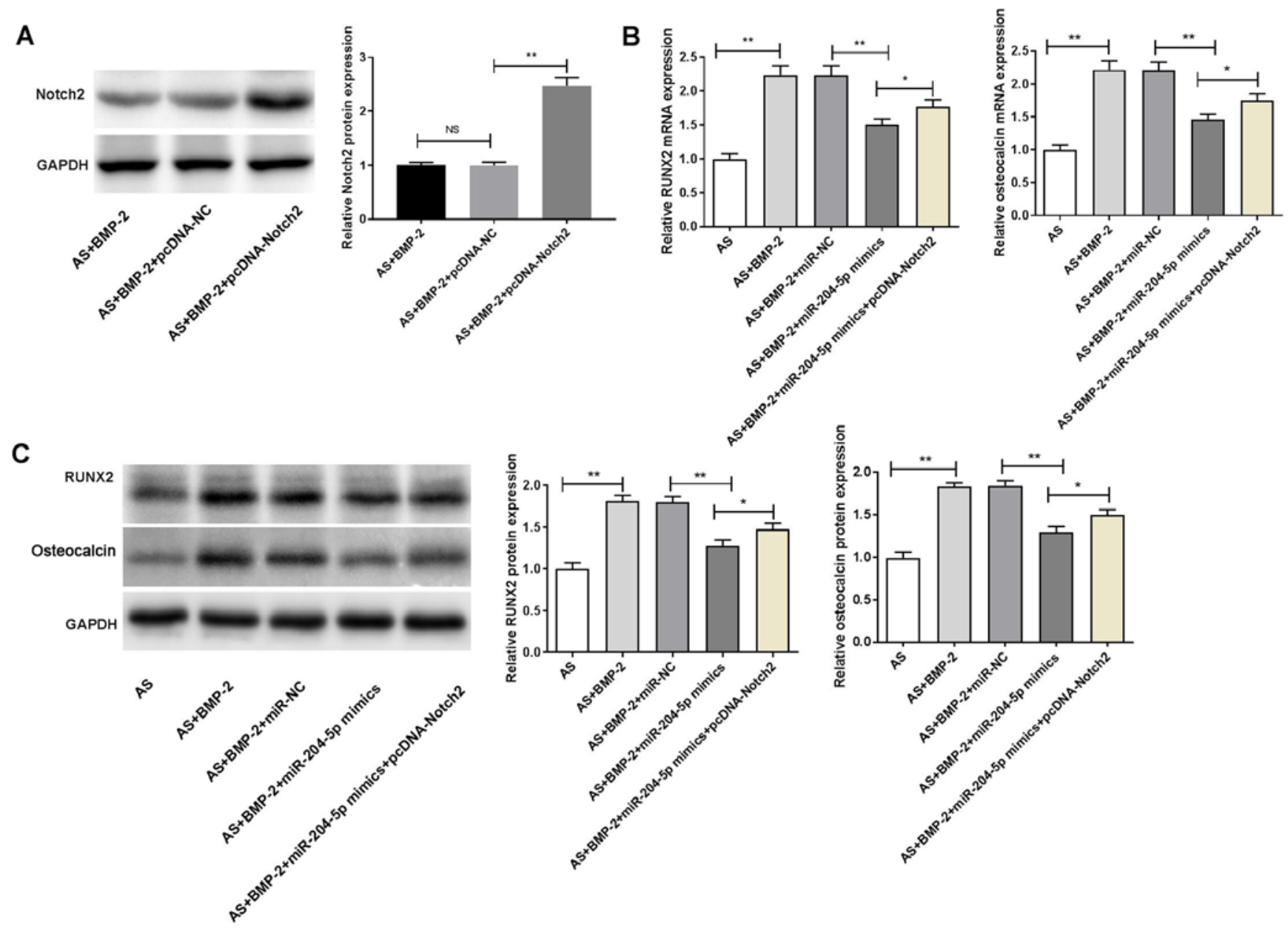

Figure 5. $m i R-204-5 p$ inhibits the expression of RUNX2 and osteocalcin. (A) Notch2 protein expression following transfection with pcDNA-Notch2. (B) mRNA expression of RUNX2 and osteocalcin. (C) Protein expression of RUNX2 and osteocalcin. GAPDH was used as the internal control. "P<0.05 vs. the AS + BMP-2 + miR-204-5p mimics group; ${ }^{* *} \mathrm{P}<0.01$ vs. the AS and AS + BMP-2 + miR-NC groups, respectively. miR, microRNA; RUNX2, runt-related transcription factor 2; AS, ankylosing spondylitis; BMP-2, bone morphogenetic protein 2; NC, negative control.

functions in inhibiting the osteogenic differentiation of AS fibroblasts by targeting RUNX2 (41).

RUNX2 and osteocalcin are key factors involved in the bone-repair process (42). The level of RUNX2 mRNA is higher in patients with AS than that in healthy controls (43). RUNX2 controls the differentiation and formation of osteoblasts by upregulating the transcription of the BMP-2 gene to differentiate osteoblast precursors into osteocytes (44). Furthermore, suppressing RUNX2 can initiate osteogenic differentiation, which participates in the anti-osteogenic differentiation of AS fibroblasts (45). The results of the present study indicated that $m i R-204-5 p$ inhibited the osteogenic differentiation of fibroblasts by inhibiting RUNX2 expression. Yu et al (41) demonstrated that miR-204-5p positively regulates RUNX2 expression to promote osteogenic differentiation of calcific aortic valve disease. Conversely, Wang et al (46) reported that $m i R-204$ inhibits RUNX2 expression and plays a negative role in regulating osteogenic differentiation. These previous findings suggest that the inhibition of RUNX2 expression contributes to the inhibitory effect induced by $m i R-204-5 p$ on osteogenic differentiation.

Osteocalcin is the principle non-collagen component of the bone, which is considered a specific indicator of bone formation (47). Osteocalcin expression is notably higher in patients with AS than that in the control group (48). Furthermore, osteocalcin expression is significantly higher in patients with ankle stiffness and hip involvement than that in healthy controls (49). In the current study, osteocalcin expression was decreased in AS. miR-204-5p controls the osteogenic differentiation of fibroblasts by inhibiting osteocalcin expression (31). Thus, when $m i R-204-5 p$ is inhibited, osteocalcin expression increases (31). Additionally, the expression of osteocalcin is downregulated by inhibiting RUNX2 expression and disrupting the activation of RUNX2 (50). Taken together, these results suggest that $m i R-204-5 p$ is an important target to inhibit osteogenic differentiation through inhibiting the expression of RUNX2 and osteocalcin.

The current study had some limitations. Firstly, a relatively small number of studies have come from China, which limited the ability to identify the relationships between the $m i R-204-5 p$ and AS. Moreover, the mechanism of $m i R-204-5 p$ regulation on AS was only based on the experiments in vitro, and thus requires further investigation in vivo. In addition, the detailed mechanisms of action of $m i R-204-5 p$ on AS are yet to be elucidated. 
The present study investigated the osteogenic differentiation of ligament fibroblasts from patients with AS. The results demonstrated that $m i R-204-5 p$ inhibited the expression of RUNX2 and osteocalcin in AS ligament fibroblasts by targeting Notch2, which provides a theoretical basis for the effective treatment of AS.

\section{Acknowledgements}

Not applicable.

\section{Funding}

No funding was received.

\section{Availability of data and materials}

The datasets used and/or analyzed during the current study are available from the corresponding author on reasonable request.

\section{Authors' contributions}

JZ: Substantial contributions to the conception and design of the work. YZ: Substantial contributions to acquisition of data. BL: Substantial contributions to interpretation of data. JZ and YZ: Performed the experiments. BL: Performed the data analysis. JZ and YZ: Drafting the manuscript and revising it critically for important intellectual content. BL: Revised the manuscript for critically important intellectual content. JZ, YZ and BL: Final approval of the version to be published. JZ, YZ and BL: Agreement to be accountable for all aspects of the work in ensuring that questions related to the accuracy or integrity of any part of the work are appropriately investigated and resolved. All authors read and approved the final manuscript.

\section{Ethics approval and consent to participate}

The present study was approved by the Ethics Committee of Shouguang People's Hospital (Shouguang, China; approval no. SGSRMXY-2020-09) and written informed consent was provided by all patients prior to the study start.

\section{Patient consent for publication}

Not applicable.

\section{Competing interests}

The authors declare that they have no competing interests.

\section{References}

1. Robinson PC, Leo PJ, Pointon JJ, Harris J, Cremin K, Bradbury LA, Stebbings S, Harrison AA; Australian Osteoporosis Genetics Consortium; Wellcome Trust Case Control Consortium, et al: Exome-wide study of ankylosing spondylitis demonstrates additional shared genetic background with inflammatory bowel disease. NPJ Genom Med 1: 16008, 2016.
2. Zhao J, Huang C, Huang H, Pan JK, Zeng LF, Luo MH, Liang GH, Yang WY and Liu J: Prevalence of ankylosing spondylitis in a Chinese population: A systematic review and meta-analysis. Rheumatol Int 40: 859-872, 2020.

3. Raychaudhuri SP and Deodhar A: The classification and diagnostic criteria of ankylosing spondylitis. J Autoimmun 48: 128-133, 2014.

4. Ahsan T, Erum U, Jabeen R and Khowaja D: Ankylosing Spondylitis: A rheumatology clinic experience. Pak J Med Sci 32: 365-368, 2016

5. Dean LE, Jones GT, MacDonald AG, Downham C, Sturrock RD and Macfarlane GJ: Global prevalence of ankylosing spondylitis. Rheumatology (Oxford) 53: 650-657, 2014.

6. Jethwa $\mathrm{H}$ and Bowness P: The interleukin (IL)-23/IL-17 axis in ankylosing spondylitis: New advances and potentials for treatment. Clin Exp Immunol 183: 30-36, 2016.

7. Darby SC, Doll R, Gill SK and Smith PG: Long term mortality after a single treatment course with X-rays in patients treated for ankylosing spondylitis. Br J Cancer 55: 179-190, 1987.

8. Silte Karamanlioğlu D, Aktas I, Ozkan FU, Kaysin M and Girgin N: Effectiveness of ultrasound treatment applied with exercise therapy on patients with ankylosing spondylitis: A double-blind, randomized, placebo-controlled trial. Rheumatol Int 36: 653-661, 2016.

9. Wang T, Wang D, Cong Y, Yin C, Li S and Chen X: Evaluating a posterior approach for surgical treatment of thoracolumbar pseudarthrosis in Ankylosing Spondylitis. Clin Spine Surg 30: E13-E18, 2017.

10. Wang M, Wang L, Zhang X, Yang X, Li X, Xia Q, Chen M, Han R, Liu R, Xu S and Pan F: Overexpression of miR-31 in Peripheral Blood Mononuclear Cells (PBMC) from patients with Ankylosing Spondylitis. Med Sci Monit 23: 5488-5494, 2017.

11. Perez-Sanchez C, Font-Ugalde P, Ruiz-Limon P, Lopez-Pedrera C, Castro-Villegas MC, Abalos-Aguilera MC, Barbarroja N, Arias-de la Rosa I, Lopez-Montilla MD, Escudero-Contreras A, et al: Circulating microRNAs as potential biomarkers of disease activity and structural damage in Ankylosing Spondylitis patients. Hum Mol Genet 27: 875-890, 2018.

12. He H, Chen K, Wang F, Zhao L, Wan X, Wang L and Mo Z: miR-204-5p promotes the adipogenic differentiation of human adipose-derived mesenchymal stem cells by modulating DVL3 expression and suppressing Wnt $/ \beta$-catenin signaling. Int J Mol Med 35: 1587-1595, 2015.

13. Wang Y, Niu ZY, Guo YJ, Wang LH, Lin FR and Zhang JY: IL-11 promotes the treatment efficacy of hematopoietic stem cell transplant therapy in aplastic anemia model mice through a NF- $\kappa \mathrm{B} / \mathrm{microRNA}-204 /$ thrombopoietin regulatory axis. Exp Mol Med 49: e410, 2017.

14. Roozbehkia M, Mahmoudi M, Aletaha S, Rezaei N, Fattahi MJ, Jafarnezhad-Ansariha F, Barati A and Mirshafiey A: The potent suppressive effect of $\beta$-d-mannuronic acid (M2000) on molecular expression of the TLR/NF-kB Signaling Pathway in ankylosing spondylitis patients. Int Immunopharmacol 52: 191-196, 2017.

15. Wang G, Cai J, Zhang J and Li C: Mechanism of triptolide in treating ankylosing spondylitis through the anti-ossification effect of the BMP/Smad signaling pathway. Mol Med Rep 17: 2731-2737, 2018.

16. Zou Y, Yang X, Yuan S, Zhang P, Ye Y and Li Y: Downregulation of dickkopf-1 enhances the proliferation and osteogenic potential of fibroblasts isolated from ankylosing spondylitis patients via the Wnt/ $\beta$-catenin signaling pathway in vitro. Connect Tissue Res 57: 200-211, 2016.

17. Xu W,Liang CG,Li YF, Ji YH, Qiu WJ and Tang XZ: Involvement of Notch1/Hes signaling pathway in ankylosing spondylitis. Int J Clin Exp Pathol 8: 2737-2745, 2015.

18. Zhou Y, Tanzie C, Yan Z, Chen S, Duncan M, Gaudenz K, Li H, Seidel C, Lewis B, Moran A, et al: Notch2 regulates BMP signaling and epithelial morphogenesis in the ciliary body of the mouse eye. Proc Natl Acad Sci USA 110: 8966-8971, 2013.

19. Ruan ZB, Fu XL, Li W, Ye J, Wang RZ and Zhu L: Effect of notch1,2,3 genes silicing on NF- $\kappa \mathrm{B}$ signaling pathway of macrophages in patients with atherosclerosis. Biomed Pharmacother 84 : 666-673, 2016.

20. Smith DM, Cooper GM, Mooney MP, Marra KG and Losee JE: Bone morphogenetic protein 2 therapy for craniofacial surgery. J Craniofac Surg 19: 1244-1259, 2008.

21. Khosla S, Westendorf JJ and Oursler MJ: Building bone to reverse osteoporosis and repair fractures. J Clin Invest 118: 421-428, 2008 
22. Sun J, Li J, Li C and Yu Y: Role of bone morphogenetic protein-2 in osteogenic differentiation of mesenchymal stem cells. Mol Med Rep 12: 4230-4237, 2015.

23. van der Linden SM, Valkenburg HA, de Jongh BM and Cats A The risk of developing ankylosing spondylitis in HLA-B27 positive individuals. A Comparison of Relatives of Spondylitis patients with the general population. Arthritis Rheum 27: 241-249, 1984.

24. Hupkes M, Sotoca AM, Hendriks JM, van Zoelen EJ and Dechering KJ: MicroRNA miR-378 promotes BMP2-induced osteogenic differentiation of mesenchymal progenitor cells. BMC Mol Biol 15: 1, 2014.

25. Kanayama S, Kaito T, Kitaguchi K, Ishiguro H, Hashimoto K, Chijimatsu R, Otsuru S, Takenaka S, Makino T, Sakai Y, et al: ONO-1301 Enhances in vitro osteoblast differentiation and in vivo bone formation induced by bone morphogenetic protein. Spine (Phila Pa 1976) 43: E616-E624, 2018.

26. Jung JI, Park KY, Lee Y, Park $M$ and Kim J: Vitamin C-linker-conjugated tripeptide AHK stimulates BMP-2-induced osteogenic differentiation of mouse myoblast $\mathrm{C} 2 \mathrm{C} 12$ cells Differentiation 101: 1-7, 2018.

27. Livak KJ and Schmittgen TD: Analysis of relative gene expression data using real-time quantitative PCR and the 2(-Delta Delta C(T)) method. Methods 25: 402-408, 2001.

28. Qin X, Jiang T, Liu S, Tan J, Wu H, Zheng L and Zhao J: Effect of metformin on ossification and inflammation of fibroblasts in ankylosing spondylitis: An in vitro study. J Cell Biochem 119: 1074-1082, 2018

29. Zou YC, Yang XW, Yuan SG, Zhang P and Li YK: Celastrol inhibits prostaglandin E2-induced proliferation and osteogenic differentiation of fibroblasts isolated from ankylosing spondylitis hip tissues in vitro. Drug Des Devel Ther 10: 933-948, 2016.

30. Zhou YY, Huang RY, Lin JH, Xu YY, He XH and He YT: Bushen-Qiangdu-Zhilv decoction inhibits osteogenic differentiation of rat fibroblasts by regulating connexin 43. Exp Ther Med 12: 347-353, 2016

31. Yu F, Cui Y, Zhou X and Han J: Osteogenic differentiation of human ligament fibroblasts induced by conditioned medium of osteoclast-like cells. Biosci Trends 5: 46-51, 2011.

32. Shang G, Wang Y, Xu Y,Zhang S, Sun X, Guan H,Zhao X, Wang Y, Li Y and Zhao G: Long non-coding RNA TCONS_00041960 enhances osteogenesis and inhibits adipogenesis of rat bone marrow mesenchymal stem cell by targeting miR-204-5p and miR-125a-3p. J Cell Physiol 233: 6041-6051, 2018.

33. Zhang YY, Zhou JB, Zeng XW, Zhao FM and Zhan XQ: Effects of puerarin on proliferation of osteoblasts and Runx2-targeting miRNAs. Chinese Pharmacological Bulletin 32: 1457-1462, 2016.

34. Zhao J, Wang C, Song Y and Fang B: Arsenic trioxide and microRNA-204 display contrary effects on regulating adipogenic and osteogenic differentiation of mesenchymal stem cells in aplastic anemia. Acta Biochim Biophys Sin (Shanghai) 46: 885-893, 2014

35. Lee H, Kim KR, Cho NH, Hong SR, Jeong H, Kwon SY, Park KH, An HJ, Kim TH, Kim I, et al: MicroRNA expression profiling and Notch1 and Notch 2 expression in minimal deviation adenocarcinoma of uterine cervix. World J Surg Oncol 12: 334, 2014.

36. Cai B, Zheng Y, Ma S, Xing Q, Wang X, Yang B, Yin G and Guan F: BANCR contributes to the growth and invasion of melanoma by functioning as a competing endogenous RNA to upregulate Notch2 expression by sponging miR-204. Int J Oncol 51: 1941-1951, 2017.
37. Hayes AJ, Dowthwaite GP, Webster SV and Archer CW: The distribution of Notch receptors and their ligands during articular cartilage development. J Anat 202: 495-502, 2003.

38. Wei Y, Mou D, Lian J, Luo J and Tang M: Role of Notch signaling in BMP2-induced osteogenic differentiation of MEFs and its mechanism. Chin J Cell Biol 40: 478-489, 2018.

39. Wegman F, Bijenhof A, Schuijff L, Oner FC, Dhert WJ and Alblas J: Osteogenic differentiation as a result of BMP-2 plasmid DNA based gene therapy in vitro and in vivo. Eur Cell Mater 21: 230-242, 2011

40. Song R, Fullerton DA, Ao L, Zhao KS and Meng X: An epigenetic regulatory loop controls pro-osteogenic activation by TGF- $\beta 1$ or bone morphogenetic protein 2 in human aortic valve interstitial cells. J Biol Chem 292: 8657-8666, 2017.

41. Yu C, Li L, Xie F, Guo S, Liu F, Dong N and Wang Y: LncRNA TUG1 sponges miR-204-5p to promote osteoblast differentiation through upregulating Runx2 in aortic valve calcification. Cardiovasc Res 114: 168-179, 2018.

42. Liu Z, Yao X, Yan G, Xu Y, Yan J, Zou W and Wang G: Mediator MED23 cooperates with RUNX2 to drive osteoblast differentiation and bone development. Nat Commun 7: 11149, 2016.

43. Huang J, Song G, Yin Z, Fu Z and Ye Z: MiR-29a and messenger RNA expression of bone turnover markers in canonical Wnt pathway in patients with ankylosing spondylitis. Clin Lab 63: 955-960, 2017.

44. Yang LQ, Dong CJ and Zhu S: Osteogenesis-related factor Runx2 expression in necrotic femoral head tissue: Study protocol for a non-randomized, parallel-controlled trial. Chinese Journal of Tissue Engineering Research 2016.

45. Zhou YY, Liu HX, Jiang N, Feng XH, Feng XY, Zhang HQ Wu ZK, Liang HY, Jiang Q and Chen P: Elemene, the essential oil of Curcuma wenyujin, inhibits osteogenic differentiation in ankylosing spondylitis. Joint Bone Spine 82: 100-103, 2015.

46. Wang Y, Chen S, Deng C, Li F, Wang Y, Hu X, Shi F and Dong N: MicroRNA-204 targets Runx2 to Attenuate BMP-2-induced osteoblast differentiation of human aortic valve interstitial cells. J Cardiovasc Pharmacol 66: 63-71, 2015.

47. Franck H and Keck E: Serum osteocalcin and vitamin D metabolites in patients with ankylosing spondylitis. Ann Rheum Dis 52: 343-346, 1993

48. Kwon SR, Lim MJ, Suh CH, Park SG, Hong YS, Yoon BY, Kim HA, Choi HJ and Park W: Dickkopf-1 level is lower in patients with ankylosing spondylitis than in healthy people and is not influenced by anti-tumor necrosis factor therapy. Rheumatol Int 32: 2523-2527, 2012

49. Solmaz D, Bulbul H, Uslu S, Kozaci LD, Karaca N and Akar S: AB0157 serum level of the vascular endothelial growth factor is elevated in Ankylosing Spondylitis and Osteocalcin may be related with osteoproliferation. BMJ 74 (Suppl 2): AB0157, 2015.

50. Jeon MJ, Kim JA, Kwon SH, Kim SW, Park KS, Park SW, Kim SY and Shin CS: Activation of peroxisome proliferator-activated receptor-gamma inhibits the Runx2-mediated transcription of osteocalcin in osteoblasts. J Biol Chem 278: 23270-23277, 2003.

This work is licensed under a Creative Commons Attribution-NonCommercial-NoDerivatives 4.0 International (CC BY-NC-ND 4.0) License. 